\title{
De la locura y la inseguridad del derecho a la racionalidad y el orden de la ley. Lectura dialéctica de Thomas Hobbes
}

\author{
From mandness and insecurity of right to rationality \\ and order of law. A dialectic reading of Thomas Hobbes
}

\author{
Pedro Luis Blasco AzNar
}

Universidad de Zaragoza

\begin{abstract}
Resumen. Asumo como punto de partida la antinomia antropológica de la naturaleza individual/social del hombre, que se constituye en el pensamiento de Hobbes, políticamente, como la antinomia indviduo/sociedad, cuya expresión jurídica da lugar a la antinomia derecho/ley, en su concepción iusnaturalista, que refleja asimismo la antinomia antropológica pasión/razón. Tal concepción dialéctica sólo está implícita en su Filosofía Política y Filosofía del Derecho, pero se hace bien patente si analizamos la antropología subyacente en ella. Por lo tanto, los problemas que esta dialéctica origina requieren una solución o salida dialéctica de acuerdo a la dialecticidad de su fundamento antropológico. Por eso la filosofía jurídica y política de Hobbes no pudo ni puede ser adecuada ni efectiva sino parcial o negativamente.
\end{abstract}

Palabras clave: Thomas Hobbes, derecho, ley, filosofía política, antropología, dialéctica.

\section{Introducción}

La antinomia política individuo/sociedad es primero, de suyo, una antinomia antropológica entre la individualidad y la sociabilidad de cada ser humano como ele-
ABSTRACT. I take for granted as a starting-point the anthropological antinomy on the individual/social nature of man. This antinomy is constituted politically in Hobbes' thought as the antinomy individual/society, whose legal expression gives rise to the antinomy right/law —in his iusnaturalist conception - which reflects as well the anthropological antinomy passion/reason. This dialectical conception is only implicit in his political and legal philosophy; however, it becomes obvious if the underlying anthropology is analysed. Therefore, the problems derived from this dialectics require a dialectical solution in accordance with the dialecticity of its anthropological foundation. That is why Hobbes' legal and political philosophy was not and is not still adequate or effective, but in a partial or negative way.

Key words: Thomas Hobbes, right, law, political philosophy, anthropology, dialectic.

mentos constitutivos o intrínsecos de su naturaleza humana. Si el hombre no fuera por naturaleza individual y social no habría esa oposición entre el individuo y la sociedad con intereses opuestos, no habría individuo y sociedad que pudieran 
enfrentarse. Ahora bien, en Hobbes esta antinomia política tiene también la expresión y la forma bien desarrollada, núcleo central de su filosofía, de la que he llamado antinomia jurídica derecho/ley. Quiero llamar la atención sobre el hecho de que esta antinomia tiene también, a su vez, un carácter y fundamento antropológico en la antinomia pasión/razón como dos elementos constitutivos de la naturaleza del ser humano. Si la naturaleza humana no fuera pasional y racional, si no tuviéramos o fuéramos pasión y razón, no habría conflicto. Así, pues, las antinomias antropológicas llevan necesariamente a las antinomias política y jurídica, lo cual significa que la política y lo jurídico tienen de suyo, por su fundamentación antropológica más radical, una dimensión dialéctica esencial. Por lo tanto, hay problemas políticos y jurídicos que han de resolverse dialécticamente de acuerdo a la dialéctica originaria de la naturaleza humana, de la especie que he denominado dialéctica de complementariedad. No vale suprimir la individualidad en favor de la sociabilidad, ni suprimir la sociabilidad en favor de la individualidad absoluta. No vale anular la pasión a favor de la razón, ni anular la razón en favor de liberar absolutamente la pasión. En ambos casos, lo que acabaría siendo suprimido sería la misma naturaleza humana. Consecuentemente, en lo jurídico, tampoco cabe anular el derecho para hacer prevalecer absolutamente la ley, un poder de legislar absoluto, ni negar la ley para potenciar un derecho absoluto. Hobbes, seguramente, no fue consciente de la dialecticidad antropológica de su problema político y jurídico y no lo pudo resolver adecuadamente; es decir, su propuesta política y jurídica es insuficiente.

Nos hallamos en la entrada de la modernidad, cuando el hombre abandona creencias milenarias no sustituidas todavía por las que habrían de distinguir al ra- cionalismo moderno, escribió Ortega y Gasset a este respecto ${ }^{1}$. Pero estamos también en los inicios del Estado liberal que ya se planteaba la cuestión del límite de la libertad individual, dónde y cómo poner el control, etc., problema que Hobbes resolvería en su teoría de la sociedad y del Estado, fundamentada en el derecho natural, inspirándose quizás, como sugiere Bernhardt, en la tesis sofística que en el libro II de la República de Platón da nacimiento al contractualismo ${ }^{2}$.

El sistema que desarrolla Hobbes contiene las tres partes de su proyecto primero en el que se había de ocupar del estudio de los cuerpos, del hombre y del ciudadano, y en cuyo desarrollo quiere mostrar una perfecta continuidad que nos muestra la unidad del sistema: «Hobbes intentó comprender el mundo social a través de movimientos mecánicos de atracción y repulsión» ${ }^{3}$, señalan diversos autores como Salvador Giner. Es así como Hobbes vio que «con sólo que se pudieran poner al descubierto las causas actuantes en los sentidos y en la razón del hombre, se podría avanzar desde el conocimiento del mecanismo del individuo hasta captar la ciencia de todo el cuerpo político...» ${ }^{4}$. Esto es lo que Hobbes mismo decía al Conde de Devonshire: «Si se conociera la razón de las acciones humanas con la misma certeza con la que se conoce la razón de las dimensiones en las figuras, quedarían desarmadas la ambición y la avaricia... y el género humano gozaría de una paz...» ${ }^{5}$.

La obra de Hobbes es también un ataque a la causa principal que obstaculiza la formación de la unidad estatal: la autoridad religiosa, por proclamarse «titular legítima de un poder superior al del Estado». Más de la tercera parte del $D e$ cive y casi la mitad de Leviatán los dedica Hobbes, puntualiza N. Bobbio, a su «preocupación por resolver el problema de las relaciones entre Iglesia y Esta- 
do» ${ }^{6}$. También están en su horizonte otras cuestiones más particularmente inglesas como la disputa entre la Corona y el Parlamento, la primacía del Common Law sobre el Statute Law, etc. Todo lo cual llevaría a Hobbes a pensar una original filosofía en la que el nuevo cuerpo político fue concebido, como dice H. Arendt, «en beneficio de la nueva sociedad burguesa tal como emergía en el s. XVII» ${ }^{7}$.

Asimismo, me interesa aquí poner de relieve el carácter individualista del sistema hobbesiano; individualismo que, como se ha señalado alguna vez, es «el elemento plenamente moderno de Hobbes», de la misma manera que, según J. M. Bermudo, lo original y sugestivo de su pensamiento es «su fuerza por pensar el hombre como ser solitario, dependiente de sí mismo en el medio hostil donde el reconocimiento por los otros no es sino el dominio sobre ellos»» ${ }^{8}$. Paralelamente, Hobbes rechaza en su nominalismo todo concepto universal, como la idea de bondad, lo hermoso, la codicia, el poder, etc. así como el considerar la bondad, por ejemplo, una propiedad natural de un determinado tipo de cosas, hechos, etc. lo cual lleva, escribe en Leviatán, a que sea cada persona la que toma como bueno o malo un acto, una cosa, hinc et nunc, en cuanto lo considera objeto de su apetito o aversión, respectivamente. Incluso la salida y la solución al conflicto que Hobbes propone en Leviatán es, como el conflicto mismo, esencialmente individualista: cada ciudadano ha de buscar la paz «para su propio bien» ${ }^{9}$. Podemos hacer nuestro el criterio de Gauthier según el cual Hobbes construye una autoridad política ilimitada a partir de un individualismo ilimitado que no confía en la buena voluntad de los hombres. Hobbes es el gran pensador, escribió H. Arendt, «que en bien del interés particular concibió y esbozó una comunidad cuyas bases y cuyo fin último es la acumulación de poder. Hobbes, desde luego, es el único gran filósofo al que la burguesía puede reivindicar justa y exclusivamente como suyo» ${ }^{10}$.

\section{Derecho y ley: Antropología dialéctica de Hobbes}

De una forma u otra, Hobbes trata en todas sus obras de la naturaleza del hombre como tal y de su situación en la República. La antinomia individuo/sociedad la vamos descubriendo bien explícita en su pensamiento socio-político y jurídico, y su estudio requiere partir del individuo, del sujeto humano, siguiendo el pensamiento expreso del autor. Ahora bien, a propósito de dos descripciones opuestas de la naturaleza humana que encuentro en su lectura - las que, respectivamente, sirven de fundamento a su filosofía del derecho natural y a su concepción de la ley natural-, intento hacer también expreso lo que está implícito en ambas y, mediante su análisis interno, mostraré las implicaciones de una y otra, cuál es la relación real entre ellas, mediante una reflexión coherente sobre un Hobbes que a veces es más bien contradictorio; lo cual me llevará a una reinterpretación de la solución y de la salida hobbesiana a la situación contradictoria que se había creado. Por lo tanto, la investigación de esta antinomia, que también la encontramos en J. J. Rousseau aunque con rasgos peculiares ${ }^{11}$, pondrá de manifiesto al mismo tiempo la validez y operatividad o eficacia del modelo dialéctico para la filosofía política y jurídica de Hobbes, como ya expuse en otro estudio sobre filosofía moral.

\section{a) De la naturaleza humana: el derecho natural}

En los Elementos Hobbes explica que todo conocimiento, concepción, etc. del 
futuro depende de la fuerza o poder actual capaz de producirlo; tal poder está constituido por las mismas facultades del cuerpo y de la mente - así lo había expuesto Hobbes en el capítulo I de la primera parte - y por otras cosas como riqueza, autoridad, amistad, etc. pues como dice en Leviatán «el poder de un hombre... viene determinado por sus medios actuales para obtener el bien futuro aparente» ${ }^{12}$. Ahora bien, como el poder que un individuo tiene es limitado o condicionado por el que tiene cada uno de los demás, se concluye que en definitiva «el poder consiste simplemente en el exceso de poder de uno sobre el de otro» ${ }^{13}$. $\mathrm{Al}$ reconocimiento de ese poder se llama honor, de manera que honrar a alguien es admitir, mediante signos externos, la superioridad de su poder; Hobbes deja muy claro que tanto puedes tanto vales, tanto cuanto uno es cotizado por el comprador: «el valor de un hombre es, como en todas las demás cosas su precio; es decir, lo que se ofrecería por el uso de su poder» ${ }^{14}$. Incrementar este plus de poder sobre el de otro es lo que importa: «no altera su honor el que una acción (siendo grande y difícil y, en consecuencia, signo de gran poder) sea justa o injusta» ${ }^{15}$. Tampoco hay ya bueno ni malo, mío ni tuyo; el poder victorioso y triunfante siempre se justifica, piensa Hobbes. Hay que ser temible «porque es ley natural en la guerra, donde ser temido constituye una protección que tiene el hombre por su propio poder» ${ }^{16}$; y ya que, por otra parte, es instrumento de la felicidad entendida como el «continuo progreso del deseo desde un objeto a otro», porque de lo que se trata es no sólo de disfrutar una vez sino de asegurar el camino de todo deseo futuro. El deseo de felicidad va, así, unido a un «deseo perpetuo e insaciable de poder tras poder».

La importancia que para Hobbes tiene el poder se comprende más plenamen- te en función de la condición natural del hombre expuesta en el capítulo XIII del Leviatán. La naturaleza nos ha hecho a todos los hombres iguales en nuestras «facultades corporales y mentales», pero de esta igualdad surgen tres factores importantes: la inseguridad, la competición y la gloria, de manera que los hombres «están en aquella condición que se llama guerra; y una guerra como de todo hombre contra todo hombre» ${ }^{17}$. Hobbes advierte enseguida que de esto no se deriva placer alguno, «sino, antes bien, considerable pesar». Siendo todo hombre enemigo de todo hombre, no es posible el desarrollo de la industria, el cultivo, la navegación, la construcción, los conocimientos, las artes, etc., sólo hay miedo continuo y peligro de muerte violenta y «vida solitaria, pobre, desagradable, brutal y corta». Esta es «la penosa condición en la que el hombre se encuentra de hecho por pura naturaleza...», diría poco después.

Es la autoconservación y la sobrevivencia el principio del derecho natural, y también lo es el evitar todo lo que le resulta destructivo o le arrebata los medios para ello y el hacer todo lo que ayuda a preservarla mejor, bien que incrementar el propio poder potencia progresivamente la guerra de todos contra todos. El ius naturale «es la libertad que cada hombre tiene de usar de su propio poder como él quiera para la conservación de su propia naturaleza, es decir, de su propia vida» ${ }^{18}$, y de hacer, por lo tanto, todo lo que conciba como el medio más apto para ello, entendiendo allí como libertad la «ausencia de impedimentos externos» que limiten su propio poder. De ahí que en esta condición natural éste sea el fundamento del derecho natural: «que cada uno proteja cuanto pueda su vida y su cuerpo» 19 por todos los medios que considere necesarios, estándole permitido cuanto quiera y contra quien quiera. De ahí también la 
causa del miedo recíproco que Hobbes pone expresamente como fundamento de la sociedad, o, dicho de otra manera, «toda sociedad se forma por utilidad o por vanidad; mejor dicho, a causa del amor de los hombres hacia sí mismos y no hacia sus semejantes» ${ }^{20}$. Concepción pesimista y escéptica del hombre y de su historia avalada por la enseñanza, aprendida de Tucídides, de «cuán insensata es la democracia»

Esta es la lectura que tradicionalmente se ha hecho de la antropología de Hobbes y que ha priorizado el tópico clásico del homo lupus, un modelo entre otros de la en nuestros días llamada «insociable sociabilidad». Pero es necesario leer también la otra parte, la positiva, la que permite el bienestar del hombre. Es necesario leerla porque está también escrita por Hobbes, intercalada en la anterior, como en un segundo plano y con pinceladas más dispersas. Sin embargo, esta concepción positiva es fundamental para Hobbes porque tenía la convicción de que constituía la condición de posibilidad para que el hombre pudiera sobrevivir y seguir aspirando a la felicidad y lograrla cuanto le fuera posible.

\section{b) De la naturaleza humana: la ley natural}

Una nota o indicio que llama primero la atención es la teoría de las pasiones desarrollada en el capítulo VI de Leviatán donde junto al placer, temor, valor, ambición, codicia, además del deseo de poder, hay también una consideración semejante, y hay un lugar natural para la caridad y la bondad entendida como «deseo» - $\mathrm{O}$ apetito - «de un bien para otro», y para la benevolencia o «amor de las personas por la sociedad»; incluye asimismo la piedad, consistente en la «pena ante la calamidad de otro» y «surge de la imaginación de que una calamidad semejante puede acontecernos». Por el contrario, la crueldad consiste en «el desprecio o poco sentimiento por la calamidad de otros»y proviene «de la seguridad en la propia fortuna, pues no concibo posible que hombre alguno se complazca en los grandes perjuicios ocasionados a otros hombres sin otro fin particular».

Una vez hechas estas precisiones someras, ahí las deja y sólo alguna vez hace alusión indirecta a ellas. Lo que pasa es que encajan perfectamente en un contexto de pensamiento más amplio que exige también ser tenido en cuenta. Vaya, pues, por delante que es posible empezar a pensar que no es tan fiero el lobo como lo pintan. Y una de las claves fundamentales es que el hombre, por muy animal y pasional que sea, es también racional: Hobbes está tan convencido de ello, que basa en la racionalidad del hombre la posibilidad de superar el estado de guerra al que se ve inducido por sus instintos y pasiones incontrolados. Esta segunda concepción positiva de la naturaleza humana empieza ya a limitar el ius naturale de Hobbes. Puesto que todos los hombres, por exigencia de la naturaleza, desean el bonum sibi y evitar lo penoso, sobre todo la muerte, «no resulta, pues, contrario a la razón que el hombre trate de preservar de la muerte y del dolor su cuerpo y sus extremidades» ${ }^{21}$. Por lo tanto es derecho natural «que cada hombre pueda conservar con todas sus fuerzas su propia vida y sus miembros». Esto siempre está claro. Pero ahora está igualmente claro que ese derecho del individuo se reduce a preservar su «sobrevivencia e integridad física» y a los medios «razonables» para ello sin que alcance a los demás asuntos, a todas las otras cosas; es decir, no tiene ningún fundamento una interpretación totalmente libre e irrestricta del aforismo natura dedit omnia omnibus.

Pero Hobbes había introducido firme y definitivamente desde el principio la razón limitadora o moderadora del apetito como juicio ponderado y como «ley natu- 
ral». Importa destacar que Hobbes no se refiere sin más a la razón sino a la «recta razón» como «ley natural», haciendo de ella criterio de nuestros juicios valorativos respecto al último fin natural y moral que es la supervivencia: «se hace con derecho lo que no va contra la recta razón» e, inversamente, obramos contra el derecho cuando actuamos «en contradicción con una verdad deducida de principios verdaderos mediante un razonamiento recto» ${ }^{22}$. Y pues actuar contra el derecho es actuar contra alguna ley, la recta razón es una ley natural porque también la recta razón es natural como el apetito y la pasión. Así, es ley natural «lo que dicta la recta razón en cuanto a lo que se debe hacer u omitir para conservar, tanto como nos sea posible, la vida y los miembros durante largo tiempo» ${ }^{23}$, donde «recta razón» es un «razonamiento propio y verdadero de cada uno...», y donde «verdadero» es decir «concluyente de principios verdaderos rectamente dispuestos, porque toda violación de las leyes naturales consiste en un falso razonamiento, o sea, en la estupidez de los hombres que no ven que su propia conservación exige el cumplimiento de sus deberes para con los otros hombres» ${ }^{24}$. La recta razón y la ley natural tiene en cuenta los deberes para con los otros hombres; es lo contrario, como vamos a ver, a la locura irracional y estúpida del bellum omnium contra omnes. En los Elementos ya había dicho: «dado que todos los hombres arrastrados por la violencia de sus pasiones o de sus malos hábitos hacen cosas que comúnmente se consideran contrarias a la ley natural, no es el ceder a las pasiones, o algunos errores adquiridos por costumbre, lo que constituye el derecho natural» ${ }^{25}$.

La ley natural existe desde siempre y la descubre la razón, la cual «no es menos natural en el hombre que la pasión, y es la misma para todos los hombres, porque todos los hombres están de acuerdo en su voluntad de regirse y gobernarse de suerte que alcancen sus deseos, es decir, su propio bien, lo cual es obra de la razón. Por tanto, no puede haber más ley natural que la razón, ni otro precepto de derecho natural que los que nos conducen por los caminos de la paz, cuando puede conseguirse, y de la defensa cuando no puede lograrse» ${ }^{26}$. La razón, no la locura de la pasión estúpida, es la ley natural, e implica el derecho natural a la paz, o la paz como derecho natural, camino único y necesario que posibilita la sobrevivencia, mientras que la autodefensa pasional, en cuanto quebranta las leyes naturales, es excepcional, y no puede justificar los caprichos y la crueldad porque, entonces, se viola el valor y la magnanimidad y constituye una "deshonra». Así lo confirma Hobbes en De cive: sólo se actúa con derecho actuando según la recta razón, sin tratar de engañarse ni siquiera a sí mismo con falsas razones; incluso en el «estado natural de guerra» hay que respetar las leyes, y la violación de las mismas nada tiene que ver con la autoconservación. No tiene sentido, ni si quiera en el estado de naturaleza, la embriaguez ni la crueldad; más concretamente, en el estado de naturaleza «se debe apreciar lo justo y lo injusto, y más aún, lo que se hace por necesidad, para procurar la paz, para conservarse, se hace rectamente. Fuera de eso, todo daño inferido a un hombre es violación de la ley natural e injuria contra Dios» ${ }^{27}$.

Es cierto que en otro lugar había dicho que en el estado natural no hay bueno ni malo, justo ni injusto, mío ni tuyo, porque no hay todavía lo que será después ley civil; pero sí hay un criterio natural y moral y posibilidad de valorar y juzgar la conducta; hay, incluso en el estado natural de guerra, junto al derecho de la propia defensa, una «inclinación a la paz» ${ }^{28}$. Inclinación que es ley, obligación o precepto natural: no es que llegue a ser ley, 
sino que es el hombre el que llega a descubrirla como ley y lo es, precisamente, en la grave situación en que se halla por no haberla reconocido antes. Esta ley es la primera y fundamental: dice Hobbes en Leviatán que no es menos una ley natural o precepto de la razón «que todo hombre debiera esforzarse por la paz en la medida en que se espere obtenerla, y que cuando no pueda obtenerla, puede entonces buscar y usar toda la ayuda y las ventajas de la guerra» ${ }^{29}$. Ahora, una vez sentada esta ley, Hobbes deduce racionalmente las otras como la condición de posibilidad para realizar la inclinación natural a la paz y para conservar la paz una vez establecida. Así, es también ley natural que «estamos obligados a transferir a otro aquellos derechos que si son retenidos obstaculizan la paz de la humanidad», o como dice en los Elementos «es, por tanto, un precepto de derecho natural que cada uno renuncie al derecho que tiene, según la naturaleza, a todas las cosas», ya que servirse de él conduce a la guerra «y esto es contrario a la ley natural que, resumiendo, consiste en hacer la paz». Esta ley es, a su vez, ineficaz sin esta otra ley natural: «todo hombre está obligado a respetar y cumplir los convenios que ha realizado», es decir: stare pactis. En esto consiste la justicia en cuanto es «una regla de razón por la cual se nos prohíbe hacer algo destructivo para nuestra vida», y por tanto es «una ley de naturaleza». Destaquemos entre las restantes leyes la quinta: «que todo hombre se esfuerce por acomodarse al resto de los hombres», lo cual supone y manifiesta la «aptitud para la sociedad» natural en el hombre: todos ellos, por «estúpidos» que sean aferrándose a los derechos, aunque su vanagloria sea grande, etc., tienen esta ley natural y son naturalmente sociables.

Todas estas leyes naturales son obligaciones que la naturaleza humana tiene y exige a cada individuo. Se reducen por lo tanto a su objetivo común: «todos estamos obligados por la naturaleza a actuar socialmente», y esto implicaría, evidentemente, un absurdo imposible si no fuéramos ya sociables por naturaleza; porque sólo actuando y viviendo socialmente consigue el hombre la felicidad y el bienestar. $\mathrm{Si}$ «son leyes de naturaleza que prescriben la paz» es que la paz es propia de nuestra naturaleza o es nuestra condición natural. Si lo hacen «como medio de conservación del hombre en multitud» ${ }^{30}$, es que tal conservación es propia de nuestra naturaleza o es nuestra condición natural, de manera que tales leyes son distintos aspectos, condiciones, etc. en que consiste esa conservación pacífica. Son preceptos que la naturaleza humana exige para ser posible y viable ella misma: es la misma naturaleza la que controla sus propios derechos naturales, sus propias pretensiones y sus propias fuerzas y poderes. Su legitimidad se basa en la naturaleza misma, por eso en cuanto leyes naturales, inmutables y eternas, también «obligan in foro interno»; hay que esforzarse en obedecerlas y «la naturaleza razonable no nos obliga a más» ${ }^{31}$. En cuanto leyes «naturales» su característica esencial es precisamente ésta, la de ser «naturales», es decir, no convencionales sino pre-contractuales; son por naturaleza innegociables: «la injusticia, la ingratitud, la arrogancia, el orgullo, la iniquidad, el favoritismo de personas y demás no pueden nunca hacerse legítimos, porque no puede ser que la guerra preserve la vida y la paz la destruya»» ${ }^{32}$. Lo que es insociable y obstáculo para la convivencia social destruye la vida porque la vida es naturalmente vida-con o convivencia; y el que así vive es justo. Las leyes naturales son tan naturales que no necesitan ser publicadas ni promulgadas, son acordes con la razón de todos y se contienen en una sola sentencia apro- 
bada por todos, que no han de inventar los hombres y es también en los Elementos la regla evidente según la cual quod tibi fieri non vis alteri non faceris ${ }^{33}$.

Las leyes naturales, por oposición a las leyes positivas, y en virtud de las características mencionadas son también leyes morales «pues consisten en las virtudes morales como la justicia y la equidad, y en los hábitos de la mente que conducen a la paz y la caridad» ${ }^{34}$. Por eso «la ciencia de ellas es la verdadera y única filosofía moral... la ciencia de la virtud y el vicio es la filosofía moral, y por tanto, la verdadera doctrina de las leyes de naturaleza es la verdadera filosofía moral».

He aquí una concepción esperanzada de Hobbes acerca del hombre, basada en su naturaleza legal-racional. Y es obvio que esta concepción positiva del hombre descubierta por la razón y contenida, descrita en las leyes naturales, no puede entenderse meramente como contraposición a la visión negativa anterior: hay una contraposición entre ellas y ambas son incompatibles sólo si cada una se toma absolutamente negando la otra para describir la naturaleza humana, como contenido único de la concepción del hombre. Lo cual, si además tenemos en cuenta la manera esporádica como expone su antropología positiva, dando la sensación de que la va pensando a medida que se lo exige la exposición y desarrollo de la primera, no tiene que hacernos pensar que esta concepción positiva del hombre es, por segunda, secundaria y accidental sino que, por el contrario, nos insta, curiosamente, a reconsiderar menos confiadamente y con más precaución la primera.

De esta manera, atendiendo también al contenido antropológico de cada momento, creo que no es aventurado pensar que poner en Hobbes el estado de naturaleza como estado de guerra o tomar la guerra como condición natural del hom- bre, aunque todavía fuera ser fiel a su pensamiento explícito, obliga, como ya hemos visto, a poner de manifiesto una de sus contradicciones que, forzando su esencia, concede realidad absoluta a una naturaleza humana pensada negativamente que, como consecuencia, se vuelve contra sí misa. Contradicción apenas reconocida por la historiografía contemporánea, aunque es el mismo Hobbes quien invita con frecuencia a esa interpretación. No obstante, si afirmo que no es la guerra el estado o condición o manera de ser natural del hombre, no quiero decir que de hecho no se origine la situación belicosa, sino que la misma no es necesaria por naturaleza, que su origen no se debe a una insociabilidad natural, a una radical ineptitud para la convivencia y la colaboración o a una incapacidad para la felicidad y la sobrevivencia. Pienso que descubrir la antropología positiva que Hobbes mismo no sistematizó, hubiera tenido que ser suficiente para dar razón de la sociedad, del orden y de la prosperidad individual y social; pero creo que el mismo Th. Hobbes desconfiaba de su propia teoría y de la solución que aportaba porque 1): entendía que son más fuertes las pasiones que la razón; 2): no entendió en su antropología que la autoconservación de cada uno es también obra de los otros en cuanto están implicados en ella por la trascendencia constitutiva de cada uno hacia los demás; por lo tanto Hobbes no orientó por ahí su reflexión para inducir a los hombres hacia su recíproca convivencia; y 3): por la inseguridad subjetiva de cada ciudadano y por su desconfianza en la colaboración de los demás.

\section{c) Dialéctica de la naturaleza humana.}

La dedicatoria de Hobbes en Del ciudadano, habida cuenta de la situación actual del hombre, reconoce que «no sirvió de nada para el conocimiento de la verdad 
cuanto han escrito los filósofos moralistas hasta nuestros días». Su tarea por lo tanto es exponer una teoría que no se aparte de la realidad y que proceda racionalmente. Pero creo que cometió un error desde el principio al generalizar y universalizar, desmedida y contrafácticamente, una argumentación basada en la limitada experiencia de que muchas veces los hombres se unen por un interés propio más que por amistad, benevolencia, interés común, etc. Parece que Hobbes analiza la sociedad y la naturaleza humana obteniendo unas conclusiones que, incluso para él mismo, devienen después inadmisibles y contradichas por la misma experiencia. Y entonces, en vez de rectificar la posición negativa primera, pone otra nueva que la corrija y que, eso sí, sea no menos natural. Así, por ejemplo, junto a la pasión guerrera del poder necesita Hobbes afirmar también la inclinación natural a la paz.

El mismo Hobbes, comenta ese punto Giner, «se daba perfecta cuenta del valor hipotético de su estado de naturaleza tal cual nos lo presenta» ${ }^{35}$ y él mismo sabía que hay muchos hombres moderados que viven o tienden a vivir racionalmente observando las leyes naturales. Pero el desarrollo de su filosofía humana y social acabó revelándose contradictorio en diversos aspectos de la teoría: si el pesimismo y escepticismo inicial sobre la naturaleza humana le inducen a pensar que «toda sociedad se forma por utilidad o vanidad, mejor dicho a causa del amor de los hombres hacia sí mismos y no hacia sus semejantes» ${ }^{36}$ esto, no obstante, no propiciaba las esperanzas y las pretensiones de continuidad de la sociedad ya que, señala a continuación, «el afán de gloria no puede ser la base de una sociedad numerosa ni duradera».

También en otros aspectos las conclusiones contradicen las premisas iniciales, pues como leemos en el mismo lugar «aunque las comodidades de esta vida pueden aumentarse con la ayuda recíproca, se logran mucho mejor todavía dominando a los demás que asociándose a ellos», lo cual es desmentido por la realidad misma que Hobbes presenta porque el dominio y el incremento constante de poder son determinantes de un estado natural de guerra de todos contra todos; dominio y poder que suponen erróneamente un absoluto derecho de todos a todas cosas, y derecho que, debido a la «tendencia natural» del hombre a «destrozarse mutuamente», provoca el mencionado «estado natural» que es la negación de la sociedad civil, como dice Macpherson, negación de la industria, de la construcción, de los conocimientos, de las artes, etc. que es miedo continuo, peligro de muerte violenta, «vida solitaria, desagradable, brutal y corta» ${ }^{37}$, ya que ningún hombre tiene seguridad «de vivir todo el tiempo que la (misma) naturaleza concede ordinariamente a los hombres para vivir». Por muy natural que el estado de naturaleza le pareciera a Hobbes, tuvo que reconocer cuán desfavorable es «para la conservación del género humano y de cada uno en particular»; equivale a pensar que la naturaleza se autoinduce a atentar contra sí misma. Hay un círculo vicioso, una contradicción interna. No se puede afirmar, aunque el mismo Hobbes diga cosas semejantes y aún más fuertes, que «la vida es deseo de poder, pues el poder es la garantía de la vida y de su reproducción», ya que tal como Hobbes ha explicado el poder es garantía de destrucción y sólo la Ley natural primero, y después la ley civil, es garantía de la vida ya que la vida belicosa y ambiciosa no es propiamente la vida natural sino individualismo hipertrofiado antagónico, egoísmo desmedido, distinto de un natural y saludable egoísmo, dado que, como ser vivo, cada uno tiende a su desarrollo, a su mínimo bienestar, a su supervivencia, etc. 
Puedo concluir, por consiguiente, que en la misma afirmación y descripción hobbesianas del estado de naturaleza hay elementos críticos que la niegan, que es contradictoria una concepción de la naturaleza según la cual ésta acaba por negarse a sí misma y pierde definitivamente aquello que le era connatural y a lo que por sí misma tendía. N. Bobbio, en su introducción al Del ciudadano, ve también con claridad que el estado de naturaleza «presenta una situación contradictoria y por lo tanto imposible» de la que necesariamente hay que salir. Pero sigue Bobbio aceptando como natural la inclinación a hacer daño ya que «mientras la guerra es producto de una inclinación natural» la paz es «un dictado de la razón», pasando por alto que la recta razón es «ley natural» ${ }^{38}$. Es el mismo Hobbes el que ha visto claramente la contradicción a la que conduce el admitir una naturaleza negativa en cuanto tal, pero no la profundiza ni la replantea, sino que se limita a constatarla: por un lado, «este estado de hostilidad de guerra es tal que por su misma naturaleza se destruye al matarse los hombres entre sí» ${ }^{39}$, pero por otro «ese deseo de vivir en un estado tal como el estado de libertad y el derecho de todos respecto a todo se contradice a sí mismo, puesto que cada hombre desea por imperativo natural su propio bien, al cual se opone este estado en el que hemos de suponer el respeto o contención entre hombres distintos por naturaleza y capaces de destruirse entre sí»».

Posteriormente, en Del ciudadano, su postura es la misma. Admite la contradicción creada de un bellum omnium contra omnes: «quien considera que hay que quedarse en este estado en el que todo esta permitido a todos, está en contradicción consigo mismo, puesto que cada uno busca su bien por necesidad natural, y na- die puede considerar como bien para sí esa guerra de todos contra todos, naturalmente inherente a tal estado» ${ }^{40}$. También aquí Hobbes, en vez de reconsiderar, revisando sus propios criterios, cómo ha llegado a pensar que la naturaleza se contradiga a sí misma, apela a un nuevo concepto y a una nueva estrategia que resuelva o supere el problema. Propone enseguida, como sabemos, que los hombres «deben buscar la paz mientras se dé alguna esperanza de conseguirla». Cierto que manteniendo las premisas primeras, el fundamento de esta primera ley es el temor y el miedo; no obstante, la verdadera base y razón para ello es que siendo la paz un objetivo necesario de la naturaleza para preservarse, hay que pensar que no es accidental o por casualidad que sea así; es un descubrimiento racional pero no una invención de la razón; no es la razón quien la pone sino la misma naturaleza. Todo lo cual nos lleva a pensar que no es la naturaleza tal como la pensábamos inicialmente, sino que es más coherente, supuesta su tendencia probada a desarrollarse y sobrevivir, etc. atribuirle o pensarla mediante cualidades que la hacen posible, que no mediante cualidades que la autodestruyen exigiendo por esto mismo en un segundo intento de comprensión para hacerla viable, las cualidades positivas. Un estado y condición natural que de acuerdo precisamente con sus leyes naturales conduce a la destrucción de la propia naturaleza y a la inseguridad, mal podemos entenderlo como natural. Así y todo, si hay realmente un estado de guerra, de derecho y de poder, de fuerza y de astucia, etc. ¿por qué existe?, ¿qué lo ha provocado? Los mismos textos de Hobbes proporcionan una respuesta adecuada y coherente y una reinterpretación del llamado «estado de naturaleza». 


\section{Locura orgullosa, estúpida y violenta. Crítica del estado de naturaleza}

Recordemos dos textos, respectivamente, de los Elementos y de Leviatán. El principal defecto de la mente es la locura, la cual consiste en que «alguna idea (imagination) predomina de tal modo sobre las otras, que es lo único que nos apasiona». Y poco después nos aclara que unas veces «la locura y sus grados proceden de un exceso de opinión independiente», y otras «de un falso miedo o de una humillación excesiva» ${ }^{41}$. Tema que recoge después en el c. VIII de Leviatán: "tener pasiones más fuertes y vehementes por cualquier cosa que lo que ordinariamente se ve en otros, es lo que los hombres llaman locura, de la que hay casi tantas clases como de las pasiones mismas». Y también aquí precisa luego que «la pasión cuya violencia o continuidad ocasiona locura o gran vanagloria, es comúnmente llamada orgullo, y vanidad personal, por gran desaliento mental». La relación de estos textos con el tema que estudio es muy significativa si tenemos en cuenta, como vimos, la importancia del lugar y la función que Hobbes vio en la «recta razón». $\mathrm{Al}$ afirmar el predomino del poder sobre las otras pasiones, y al definir en términos de poder las riquezas, la amistad, etc. Hobbes quería decir que el poder se sirve de todo ello para incrementarse y, en definitiva, para que el plus individual de poder de un hombre sobre otro le sirva para dominarlo y vencerlo. Lo cual es común en todos los hombres y, por lo tanto, desde el momento en que en un individuo la pasión por el poder $-\mathrm{y}$ consecuentemente la pasión por la rique$\mathrm{za}$, honor y conocimiento - no predomina en él más que lo que ordinariamente se ve que predomina en otros, todavía no lo llevaría a la locura. Pero tal pasión tiende a predominar sobre las demás pasiones y sobre los demás hombres, y tiende a incrementarse progresivamente porque necesita alcanzar ese plus de poder y aumentarlo ilimitadamente y llega a ser lo único que nos apasiona. La pasión de poder, esta voluntad de poder, deviene entonces en obsesionante locura. La pasión deviene ahora locura extravagante y el predominio de la pasión de poder se hace así no sólo tendencia constante sino «abusivamente presente». Y como locura que es, se trata de un predominio irracional incontrolado que no obedece a ninguna ley natural, a ningún precepto de la razón; es el predominio de una pasión «estúpida», según el concepto de Hobbes. Y es evidente, a mi entender, que el hecho de que sea una pasión y una tendencia común a todos los hombres, no significa que no haya locura, sino que, por el contrario, todos los hombres están igualmente locos; a menos que la locura fuera el estado natural del hombre, lo cual, además de ser una contradicción, no lo admite Hobbes que, inversamente, cuida destacar en repetidas ocasiones la existencia de los hombres cuerdos, moderados y justos.

La consecuencia que se deduce de esto es fundamental: se dice que el estado de naturaleza es un estado de guerra, que la guerra es la condición natural del hombre. Hay que decir más bien, que el estado de guerra es un estado de locura y que la guerra no es la condición natural del hombre sino la condición enloquecida de la humanidad. No es natural el estado de guerra y tampoco es natural la condición enloquecida del hombre; el estado de guerra, como el predominio e incremento irracional de poder, no es natural sino derivado y condicionado. La naturaleza, en su sabiduría, ha hecho que el homo lupus sólo sea una locura o una contradicción insostenible, inviable, autodestructiva y la naturaleza humana sería contradictoria en sí misma. 
Pero observa Hobbes que el estado de guerra es real, que hay lucha por el poder, que hay competencia por imponer el propio dominio sobre los demás, que el hombre es astuto e interesado hasta la locura: ¿cómo sería posible que por naturaleza y, a la vez, contra su supervivencia y desarrollo, haya aparecido el estado de guerra, que haya adquirido el hombre la apariencia lupusiana, que el hombre haya enloquecido, que los hombres empuñen agresivamente las armas entre sí, que el interés egoísta predomine sobre la bondad, el odio sobre el amor, la aversión sobre el deseo? No es que el hombre no sea bueno, benevolente, etc. es decir, social por naturaleza, observa Hobbes: «mi principio (la general desconfianza y miedo mutuo) no implica que los hombres sean malos naturalmente». Además «las pasiones del alma procedentes de la naturaleza animal no son malas en sí». Se trata de su adecuado conocimiento, de una nueva frónesis: "si se conociera la razón de las acciones humanas, dice Hobbes a su protector, con la misma certeza con la que se conoce la razón de las dimensiones en las figuras, quedarían desarmadas la ambición y la avaricia, cuya fuerza se apoya en las falsas opiniones del vulgo respecto de lo justo y lo injusto...».

Bien miradas, aquellas razones por las que los hombres están inclinados - no por naturaleza sino, puntualiza Hobbes, «debido a un defecto en el razonar (esto es, debido a error)»— a violar las leyes positivas son, antes, la razones por las que los hombres están inclinados a violar las leyes naturales: $1 .^{\circ}$ "por presunción de falsos principios» ${ }^{42}$. Quien más puede, más las infringe: en todas las épocas y lugares se autorizan acciones injustas por la fuerza cuando salen victoriosos quienes las cometieron. De aquí deducen que la justicia es sólo una palabra vana, que esta práctica tan generalizada no puede ser injusta, etc. $2 .^{\circ}$ por falsos maestros que interpretan mal la ley natural; $3 .^{\circ}$ por deducciones erróneas a partir de principios verdaderos por quienes razonan deprisa o se fían excesivamente de su gran entendimiento. Y entre las pasiones, la que más frecuentemente es causa de incumplimiento de la ley es la vanagloria. Ella y las pasiones del odio, lujuria, ambición y avaricia «son enfermedades unidas a la naturaleza del hombre... cuyos efectos no pueden evitarse salvo mediante un extraordinario uso de la razón (o una severidad constante en su castigo)». Ya no tiene sentido pensar en una voluntad «natural» de perjudicarse mutuamente, pues esta voluntad nace de la vanagloria y de la falsa sobrestimación de nuestras fuerzas, y aun esto sólo en algunos casos; en otros, de «la obligación y necesidad de defenderse de los primeros». Respecto a este punto N. Bobbio ha visto con acierto que, si la autoconservación es lo fundamental y la vida el primer bien de todos, se pueden sacrificar a ella «los demás bienes que, una antropología ingenua o hipócritamente optimista llama morales, y entre ellos la dignidad y la libertad. Pero qué es la dignidad para Hobbes sino una consecuencia de la vanidad? $\mathrm{Y}$ ¿qué es la libertad sino el pretexto para el desenfreno de los propios deseos?» ${ }^{43}$.

La situación guerrera del estado de naturaleza puede inducir a pensar que el hombre es malo y asocial por naturaleza, pero pienso que es más coherente interpretar el pensamiento de Hobbes entendiendo el estado de guerra como ignorancia, irracionalidad, locura, enfermedad mental, falsa o vana gloria, estupidez; y nada en Hobbes hace suponer que ninguna de estas características lo sea por naturaleza; pensar lo cual, por otra parte, sería contradictorio.

No obstante, se plantea ahora otro problema porque el estado de guerra no es efectivamente el estado natural del hombre, pero es el caso de que este esta- 
do es real y sabemos ya cómo ha sido posible. El problema ahora es salir del mismo, porque es necesario salir de él pues es insostenible, y Hobbes piensa que se contradice a sí mismo quien cree que puede permanecer en él. ¿Cuál es esa salida necesaria?

Si se trata de superar una enferma y estúpida situación de ignorancia, locura, vanagloria, es que se trata de llegar a otra de sana cordura, sabia y racional; se trata de superar un estado de guerra para lograr vivir un verdadero «estado de naturaleza». La salida está, por lo tanto, determinada positivamente por el nuevo objetivo, por el nuevo estado verdaderamente natural y, negativamente, por la supresión o eliminación de aquello que la falseaba. Es decir, no es necesario, sino imposible, salir de la naturaleza; no es necesario inventar la seguridad y la paz. Es necesario volver a la naturaleza misma para hallar y descubrir la salida y sus condiciones de posibilidad; es necesario volver a la naturaleza humana para ver cómo es ella misma y toda ella la única posibilidad de que el hombre deje de hacer el loco, supere la enfermedad individualista y lupusiana del egoísmo, del orgullo y del poder, y de que se reconcilie consigo mismo. Es el tema de la segunda antropología de Hobbes, de la antropología positiva, de la racionalidad y de la ley; es el recurso a la naturaleza racional que contiene esencial y constitutivamente los elementos necesarios para la supervivencia pacífica, creativa y feliz del hombre y de la sociedad. Así es como Hobbes lo había dicho en Leviatán: el hombre se halla en una situación de guerra estúpida, pero hay también «una posibilidad de salir de ella consistente en parte en las pasiones, en parte en su razón» ${ }^{44}$. Posibilidad que se halla por lo tanto en la misma naturaleza humana, en aquellos dos elementos mediante los cuales comprendemos con Hobbes al hombre como animal y racional: las pasiones no son en sí malas, y las hay incluso esencialmente buenas y sociales; pero aun cuando hay alguna, como sobre todo la vanagloria, que contribuye a la mutua destrucción, no es por su maldad natural sino por una estúpida ignorancia, por su violación de la leyes naturales que lleva a los hombres a un no natural estado de guerra.

Aunque en el c. XIII de Leviatán se expone la supuesta condición natural del género humano y las fatales consecuencias de la misma, si la humanidad no ha llegado al desastre de aniquilarse o de estancarse en la barbarie, sino que ha podido lograr ciertos progresos, tendremos que pensar con Hobbes que ni es el hombre tan naturalmente malo, insociable, etc. como parecía antes, ni es tan irreal y utópica la posibilidad que la naturaleza misma ofrece. Es evidente, afirma de hecho Hobbes, que «no puede ser que la guerra preserve la vida y la paz la destruya», ni es menos cierto que «toda violación de las leyes naturales consiste en un falso razonamiento, o sea, en la estupidez de los hombres que no ven que su propia conservación exige el cumplimiento de sus deberes para con los otros hombres» ${ }^{45}$.

Observemos sobre todo la relación que se ha establecido entre la autoconservación por un lado, las leyes naturales y deberes con los otros, por otra parte y, finalmente la vinculación de tales leyes y deberes entre sí. Esta relación pone de manifiesto que la conservación y supervivencia sólo es posible en un estado natural entendido, evidentemente, como el estado regido por las leyes naturales y por el cumplimiento de los deberes - derivados de estas leyes - de cada uno con los demás hombres: son deberes y obligaciones sociales, de posibilidad de convivencia de unos hombres con otros, de una relación natural y necesaria entre ellos; la naturaleza humana se manifiesta así no sólo individual sino también social y convivencial. Tales leyes y deberes no los in- 
venta la razón, sino que los descubre en nosotros mismos; no son soluciones coyunturales exigidas por la penosa y miserable condición de la humanidad, sino que proceden de la naturaleza misma.

Hay una patente incoherencia en Hobbes cuando afirma que las «leyes naturales» no son propiamente tales en tanto no sean reconocidas como tales por la ley positiva del soberano, pues sólo ésta es estrictamente ley de manera que él mismo define las leyes naturales como tales leyes, pero es el caso de que Hobbes ha tenido que recurrir a ellas previamente a esa declaración del soberano, y aún antes de que hubiera soberano, en su condición de leyes tan naturales como las pasiones, como única salida al bellum omnium. Siempre han permanecido como «inclinaciones naturales», «eternas e inmutables» dice en otras ocasiones, y no se reducen a mero objeto de cálculo racional de los medios necesarios para la conservación, aunque sea necesaria la reflexión para la salida legal y natural al conflicto creado. Por el contrario, es locura peligrosa la hipertrofia de unas pasiones que desgarran no sólo la propia naturaleza individual del sujeto sino también la sociedad misma porque lleva a la inseguridad y muerte individual y colectiva de la humanidad.

Así, es la misma naturaleza la posibilidad de salvación y liberación; es la naturaleza la que exige volver a los límites naturales aceptando como falsa, irracional, loca y estúpida una excesiva ambición y sobrevaloración de los propios derechos, de las propias fuerzas, de la propia gloria, etc. Vivir según la naturaleza es vivir en el verdadero y único viable estado de naturaleza, estado de convivencia, de vivir - no de luchar - efectivamente unos con otros. En este sentido es aceptable la opinión de G. Sabine de que si «cada hombre debe esforzarse por la paz mientras tiene la esperanza de lograr- la», este «debe» sólo significa «que cualquier otro camino resulta... destructor de la seguridad deseada» ${ }^{46}$. Así también, la transición de un estado a otro es impulsada y realizada por medio de las leyes de la naturaleza, por la propia conservación iluminada ahora por la «previsión racional», dice asimismo G. Sabine. Por la «recta razón», diríamos más propiamente, en el fondo, con el mismo Hobbes, pues lo que se descubre es un sistema inviolable, de no ser con serios perjuicios, de leyes naturales y morales: "concluyo, dice Baier, que la argumentación de Hobbes es correcta. Las moralidades son sistemas de principios cuya aceptación por todo el mundo como sobrepasando (overruling) los dictados del autointerés, es del interés de todo el mundo por igual... también tiene razón Hobbes al afirmar que la aplicación de este sistema de normas está de acuerdo con la razón sólo en condiciones de sociabilidad, es decir, cuando existen normas de comportamientos bien establecidas» ${ }^{47}$. Pero entiendo que este «acuerdo con la razón» es permanente e inmutable como la natural condición de la sociabilidad del hombre; incluso cuando todavía no existen aquellas condiciones se sociabilidad, esas normas racionales constituyen el imperativo de un deber ser necesario para superar la violencia de un derecho y de una libertad tomados absolutamente. En ese sentido podría afirmar también con Baier que es de raíz hobbesiana que «debemos ser morales porque ser moral es seguir normas destinadas a sobrepasar (over-rule) el autointerés, siempre que sea interés de todos por igual que todo el mundo deje a un lado su propio interés...» ${ }^{48}$. Lo cual admite también E. Guisán cuando interpreta a Hobbes diciendo que «la justificación de la moral surge de la imposibilidad de que yo pueda lograr ni siquiera mis objetivos en ausencia del cumplimiento de mis compromisos de equidad e imparcia- 
lidad» ${ }^{49}$. Se trata de aceptar y reconocer la condición natural del hombre, sus límites y posibilidades naturales, de manera que este conocimiento racional nos preserve de toda dominación. Los hombres, que no se habían puesto de acuerdo acerca de un bien presente, han de ponerse de acuerdo sobre un bien futuro: esto es obra de la razón, la cual enseña que también son naturalmente buenos los medios necesarios para lograrla y conservarla tales como la equidad, buena fe, modestia, misericordia, etc. que resultan ser así buenos usos y hábitos, es decir, virtudes; la ley natural, entonces, deviene en ley moral.

Esto, ciertamente, es muy hobbesiano; pero también resalta un defecto en su sistema y es que una vez ha llamado la atención sobre la locura, la estupidez, la enfermedad mental y la ignorancia; una vez que ha salido del apuro en algunos momentos comprometidos, vuelve a dejar ahí estas cosas como si fueran secundarias y distrajeran al lector del verdadero argumento y de la supuestamente verdadera concepción de la naturaleza, pasando así por alto su aplicación total, sin hacerlas operativas. Pero es importante, a mi juicio, recordarlas ya que no han vuelto a aparecer en ningún otro momento de Hobbes. No se trata solamente de decir con Macpherson, por ejemplo, que el estado de naturaleza es precisamente un estado que supone las relaciones sociales, la naturaleza social del hombre, sino que también es - quizá utópicamente- el estado de supervivencia, de convivencia pacífica, agradable y feliz. Según Macpherson está claro que Hobbes comprende al hombre como naturalmente social: «el comportamiento de los hombres en el modelo de sociedad de Hobbes es, por decirlo así, tan antisocial que, cuando lo traslada a su estado de na- turaleza hipotético, con facilidad se toma equivocadamente por una formulación del comportamiento de hombres no sociales. Se trata, sin embargo, de una formulación del comportamiento de hombres sociales, civilizados» ${ }^{50}$. Sin embargo, también Macpherson acepta y se deja llevar por la fuerza inmediata de la imagen bélica con la que Hobbes presenta el estado natural: «si por hipótesis se elimina todo temor (el temor a un soberano y a otros individuos), se sigue el estado de naturaleza pleno (el estado de guerra)», conclusión que me parece equivocada si nos fijamos en textos de Hobbes contra el mismo Hobbes, contra el más aparente o explícito Hobbes: el «pleno» estado de naturaleza, como hemos visto repetidas veces y por distintos caminos, no es un estado de guerra. Sin embargo, creo que es acertado el rechazo de Macpherson a la interpretación de Leo Strauss según la cual Hobbes consideraba que la lucha por un poder ilimitado era un apetito natural, innato, del hombre como hombre ${ }^{51}$, porque los textos aducidos por Strauss no son definitivos en este aspecto y porque Macpherson se apoya a su vez en otras afirmaciones explícitas de Hobbes como son Elements part. I, c. 14, sec. 3 y Rudiments c. I, sec. 4, bien que otros textos paralelos podrían citarse en Leviatán. Tales textos desautorizan efectivamente la interpretación de Strauss, pero tampoco apoyan la interpretación de Macpherson acerca de que «algunos luchan naturalmente por tener cada vez más poder», aunque es el hecho de que algunos ciertamente luchan por tener el poder, pero no naturalmente o por naturaleza; ni es acertado que «la lucha por el poder, la lucha por los honores puede explicarse plenamente como innata en algunos hombres» ${ }^{52}$, sino que su fundamento es el autoengaño, la locura y la estupidez. 
3. Dialéctica individuo/sociedad: naturaleza individual y social del hombre

Expuse al principio dos concepciones opuestas de la naturaleza humana y, en definitiva, es ésta el lugar en el que aparecen y se dan las demás oposiciones antinómicas. Se trata de una naturaleza humana que precisamente porque aspira y desea la conservación, el bienestar, la felicidad, pone en una marcha alocada todos sus recursos pasionales y acaba precisamente en la miseria y en la autodestrucción. Ocurre, sin embargo, que había descuidado estúpidamente — stupidlysu parte racional. Se había hecho irracional porque no reconociendo a la recta razón, se servía de su autonomía natural como hacía con sus fuerzas, con la riqueza y con los amigos, etc.: como instrumento de poder. La ausencia de la actividad autónoma de la razón provoca además la inflación del protagonismo irracional de las pasiones, las cuales traspasan locamente sus límites y su verdadera realidad natural, otorgándose un derecho natural ilimitado. La libertad en esta parte de la filosofía de Hobbes deviene libertinaje porque el individuo reclama y apela a derechos absolutos y, en cuanto tales, contradictorios.

Pero Hobbes no se retracta de ellos a pesar de que ha llevado demasiado lejos su naturalidad. Los mantiene con frecuencia con la excusa de un estado de guerra en el que no hay un poder superior común a todos: los reafirma conteniéndolos o moderándolos por el temor y el miedo, no por la fuerza de la razón, sino por las razones particulares de la fuerza. No obstante, el carácter irrestricto del poder, así como las pretensiones absolutas del derecho, exigen activar la racionalidad y la eficacia de una ley con igual rango natural para que les pueda ser contrapuesta. Es la libertad imposible sin unas obliga- ciones y restricciones intrínsecas que la posibiliten. Libertad y obligación, derechos y ley, pasión y razón, desarrollan una particular dialéctica en la filosofía individual y social de Hobbes expuesta en líneas generales en las páginas anteriores. Vamos a ver que esta dialéctica es también la dialéctica naturaleza/sociedad, individualismo/comunitarismo, subjetivismo/objetivismo, autonomía/heteronomía. Es, por lo tanto, la dialéctica guerra y paz; es el conflicto entre las pasiones que se basan primero en la inclinación natural a la conservación y después en el temor a la muerte - el cual a su vez se hace progresivamente mayor a medida que aquellos se fortalecen-, y las pasiones o deseos «de aquellas cosas que son necesarias para una vida confortable» en esta inaguantable situación o estado de guerra, y que «inclinan a los hombres hacia la paz». G. Sabine la describe como el conflicto entre «un impulso adquisitivo apresurado que engendra el antagonismo» y «un egoísmo más calculador que lleva al hombre a la sociedad» ${ }^{53}$. Es, en definitiva, la dialéctica que desarrolla la «ley del honor» y la «ley de la justicia».

Todas las antinomias mencionadas están marcadas, y no podemos sorprendernos por ello, muy directa y notoriamente por uno de aquellos rasgos fundamentales que señalé al principio como características del pensamiento de Hobbes: el individualismo. No puede asombrarnos, en efecto, que el hombre, en búsqueda de bienestar, felicidad y supervivencia acabe convirtiéndose en el animal feroz que nos pinta el c. XIII de Leviatán. No se trata de la condición natural del hombre, sino de la consecuencia de la antropología individualista hobbesiana; concepción que, vinculada a la inclinación natural a la supervivencia, la cual conlleva no sólo conservación física de la vida y del cuerpo, sino también cierto bienestar y el deseo de felicidad, común a 
todos los hombres, los lleva a una supervivencia insegura, violenta y estúpida.

Recordemos que en algún momento ya aludido, Hobbes estaba convencido de que el hombre puede de hecho conseguir realizar sus intereses, sus metas, la satisfacción de sus deseos, etc. con la ayuda de los demás, pero sobre todo mediante el poder sobre ellos, mediante la dominación. Tal vez, en el hombre de Hobbes haya nacido ya loca esta inclinación natural de la autoconservación que ha de basarse en una progresiva escalada de poder individual. Pero esta concepción que atribuye a cada hombre como tarea propia y exclusivamente como suya la de su supervivencia originando competencia, temor, inseguridad, voluntad de hacer daño, vanagloria, hostilidad y, en definitiva, una guerra de todos contra todos, esta concepción, reconoce Hobbes, ha fallado porque tales consecuencias no son precisamente las que el hombre pretendía conseguir, ni ese estado final es tan natural como el que soñaba. No es la naturaleza la que se ha equivocado; el error es de Hobbes. El error no es de la naturaleza humana como tal, sino que ha fallado la observación, el cumplimiento por el individuo de las leyes de su propia naturaleza humana racional — no sólo pasionalque se constituye como naturaleza dialéctica. El error es de Hobbes y de su sistema; pero no fue consciente de ello y así, porque el problema era interior a la naturaleza dialéctica que él ignoraba, fue incapaz de solucionarlo teóricamente reconsiderando la supuesta eficacia mayor de la dominación sobre la ayuda, suavizando su individualismo autoconservador con algunas dosis de colaboración y comunitarismo, etc. Pero no es así. Hobbes mantiene el conflicto, la contradicción interna al sistema, permanece en la oposición del hombre con el hombre, del individuo con la sociedad, y mantiene al hombre sin aptitudes naturales para una sociedad a la que por otra parte está naturalmente abocado. He aquí, por lo tanto, que aparece un estado destructivo de guerra denominado con especial eufemismo «estado de naturaleza».

Lo que Hobbes estaba oponiendo o encuentra opuesto es naturaleza y sociedad, en cuanto oposición sociedad precivil/sociedad civil, sociedad pre-republicana/república. Quedarse aquí, no obstante, es al menos no ver la última oposición, la antinomia radical constitutiva del ser humano de su naturaleza individual y social: no es sólo que el hombre dejado a sus fuerzas naturales, abandonado a todos los medios que encuentre a su mano para sobrevivir y sin el amparo de las leyes civiles positivas se opone al hombre regido por un soberano, como realización en la historia de la concepción hobbesiana del hombre. Se trata de la antinomia intrínseca a la naturaleza humana que Hobbes no supo detectar, analizar ni superar, la que desgarra al hombre como sujeto naturalmente individual $\mathrm{y}$ social.

A pesar de que en abundantes párrafos de Hobbes vemos la imagen de una aparente insociabilidad natural del hombre, leemos también en otros la apelación a una sociabilidad fáctica exigida y deseable. La autosuficiencia y la autonomía natural en Hobbes exigen para estar garantizadas el favor y la heteronomía de un soberano todo poderoso y legislador: contradictoria sociabilidad, por otra parte, del hombre que necesita a los demás sin darse cuenta de ello, pero deliberadamente los odia; está naturalmente inclinado hacia ellos, a convivir sus respectivas vidas, pero de hecho los teme. Pero Hobbes sólo necesita eso. Le basta la posibilidad de una sociabilidad externa, deseable y exigible ad hoc, de una sociabilidad fáctica y organizada que supere la naturaleza belicosa del hombre y le permita constituir una sociedad republicana por 
muy artificial o artificiosa que sea. El hombre que Hobbes nos describe en estado natural pre-republicano parecería que efectivamente era insocial por naturaleza si no fuera porque llega un momento en que es consciente de su tragedia y de su única salvación, en cuanto ambas son posibles por la misma y única naturaleza humana del hombre.

La situación real del hombre es insosteniblemente conflictiva y ha de tener una salida, y Hobbes, desde su análisis externo y circunstancial de la sociedad, busca y propone una vía de solución meramente social. Propone limitar las aspiraciones de autonomía y quedarse en la aceptación, común a todos desde luego, de un mal menor: renunciar a sus propios derechos, libertades, poderes, etc. pero no por abandono sino por transferencia. Convienen todos entre sí someterse como súbditos a un único soberano que reuniendo en sí todas las pequeñas parcelas individuales de poder, libertad y derecho tenga toda la fuerza absoluta para garantizar eficazmente la paz y la seguridad interna y externa, y la capacidad para promulgar las leyes necesarias para lograr y conservar esa paz y seguridad en todos los ámbitos de la vida de la república que así se ha formado. A partir de ahora ya no hay leyes naturales que obliguen solamente in foro interno; hay también criterios comunes para lo bueno y lo malo, lo justo y lo injusto, lo mío y lo tuyo. La libertad y la igualdad ya no son inquietantes, peligrosas, esclavizantes; ya no hay posibilidad para determinadas locuras, para la enfermedad mental de una vanagloria estúpida. Ahora ya no son los hombres meramente individuales como antes, sino los nuevos ciudadanos de una República cuya esencia consiste en ser «una persona cuyos actos ha asumido como autora una gran multitud, por pactos mutuos de unos con otros, a los fines de que pueda usar la fuerza y los medios de to- dos ellos, según considere oportuno, para su paz y defensa común» ${ }^{54}$. Al hacerse ciudadanos «han creado cadenas artificiales llamadas leyes civiles». La guerra de todos contra todos ha sido vencida por el pacto de todos con todos y de todos con el soberano; por el pactum unionis y el pactum subiectionis. Es la tierra prometida por las leyes de la naturaleza cuyo cumplimiento exigía, según Hobbes, la garantía convencional de un nuevo derecho. Se trata de «la necesidad de los pactos» y de observar «los fundamentos de la virtud moral y de los deberes civiles», cuyo cumplimiento garantiza el soberano totalitario/autoritario del que, en todo caso, como ha dicho Gauthier, ha hecho Hobbes «una autoridad política ilimitada por partir de un individualismo ilimitado que no confía en la buena voluntad de los hombres» 55 .

Desde el momento en que la autoridad queda constituida legítimamente, todos y cada uno de los individuos están en adelante obligados con ella. Obligación que, según el criterio de Oakeshott, no obedece solamente a un interés egoísta, porque tampoco el Estado es de origen meramente utilitarista, sino que es una mezcla de obligación física, racional y moral ${ }^{56}$. En cambio, creo que es infundada la discrepancia de Warrender en este punto cuando entiende no que la obligación política sea también moral, sino que no se deduce de los postulados sobre la naturaleza del hombre sino de la voluntad divina ${ }^{57}$. Vendría, en todo caso, el soberano a asumir la tarea del autocontrol no agresivo que al menos algunos hombres querían eludir o de conciencia social del individuo. La constitución de la república, del soberano y del Estado que propugna Hobbes, no siendo, ni siquiera desde su propia antropología, la más adecuada y natural solución, es parte esencial de su sistema, de su teoría política, de la que se ha podido decir que, aunque parezca pa- 
radójico, constituye el establecimiento del absolutismo sobre la base y supuestos liberales ${ }^{58}$.

Así es como vio Hobbes la salida al conflicto de una naturaleza en estado de guerra. Salida y solución que tenía teóricamente un signo externo, pero históricamente implícito o hipotético, que son los contratos social y político, y que se personaliza físicamente en el Soberano o asamblea de hombres. Pero el contrato es, como dije antes, una solución de compromiso, premeditada y exterior al verdadero conflicto de la naturaleza humana; y así, bajo su aparente corrección, captamos su insuficiencia esencial y su carácter de mera idea ejemplar y, como ha observado MacIntyre, lógicamente gratuita: la idea del contrato es otro concepto gratuito de Hobbes pues le exige dos cosas incompatibles: «quiere que sea el fundamento de todas las normas y reglas compartidas y comunes; pero quiere también que sea un contrato, y para que sea un contrato ya deben existir unas normas compartidas y comunes del tipo que, según él no puede presentarse con anterioridad al contrato... el concepto de un contrato original... no puede ser usado ni siquiera para componer una metáfora coherente» ${ }^{59}$. A mi entender, la teoría del contrato social es, en verdad una solución aparente mientras siga reconociendo junto a la paz la posibilidad de la guerra, junto a la ley de la justicia la ley del honor y como alternativa a la cooperación una siempre posible dominación; en definitiva, siguen divididos individuo y sociedad, naturaleza individual y naturaleza social del hombre.

El contractualismo de Hobbes no ha resuelto, ni podía hacerlo, definitivamente la oposición entre derecho y ley, pasión y razón. Pero el conflicto entre estas oposiciones no surge porque sólo uno de estos elementos antinómicos fuera de carácter natural frente al otro, cuya elimina- ción infundada excluiría la antinomia. Es fundamentalmente un conflicto, digamos, inter pares: Hobbes vio que ambos elementos son constitutivos de la naturaleza humana, pero creo que no vio su antinomia y su implicación recíproca, ni el carácter dialéctico de la naturaleza misma que los afirma como elementos constitutivos y que es su propio contexto real en el que se afirman, pero negándose recíprocamente como absolutos. Porque ¿cómo, si no, pueden ser naturales ambos -pasión y derecho, razón y ley—, cómo podría ser tan contradictoria la naturaleza y cómo podría la naturaleza requerir y necesitar la pasión y el derecho, y exigir después su renuncia a favor de la razón y la ley cuando ambos son constitutivos del ser humano y tienden a la supervivencia? Pero, por otra parte ¿por qué no habría de entrar el individuo en guerra mortal con todos los demás en sus respectiva tareas de supervivencia individual? Sólo cabe como respectivas respuestas que ese requerimiento no es la necesidad de una libertad y derecho absolutos, y que no se trata de supervivencia como tarea exclusivamente individual. Si hay que renunciar y restringir algo es porque hay que volver a los límites naturales, debido a que antes el hombre, en la teoría de Hobbes, ya los había sobrepasado originando un estado de guerra. Siendo ambos naturales, Derecho y Ley, no son una antítesis contradictoria, sino que se afirman y niegan recíprocamente: el derecho niega, pero no absolutamente, la ley; pero sólo es posible por ella, como Hobbes ha demostrado; y la ley niega las pretensiones absolutas del derecho, pero, a su vez, no es posible sin ser requerida por el derecho. Ambos se condicionan mutuamente, se posibilitan y se limitan recíprocamente. Y la pasión puede, asimismo, ser criterio de conducta, pero sólo como pasión natural, como pasión racional, limitada y controlada por la razón, porque de otra 
manera es pasión enferma, estúpida y loca. Así es también como la razón no es criterio único de conducta, adecuándose a la manera como la naturaleza es pasional, es decir, siendo ella en este sentido razón apasionada.

Asímismo individuo y sociedad, y primera y más radicalmente, individualidad y sociabilidad son válidas pero dialectizándose, sabiendo que no son absolutos, porque el absoluto no es: sabiendo, por consiguiente, que el individuo puede seguir sus intereses, constituir su propio criterio natural y moral de conducta, pero consciente de que él mismo, su naturaleza trascendente, es su propio límite. Consecuentemente, el contrato sólo podría valer eficazmente por la renuncia previamente exigida del derecho subjetivo individual, en cuanto reconocimiento de lo infundado de las pretensiones primeras ilimitadas, asumiendo los propios límites naturales respecto a nuestra libertad, derecho y poder. Hobbes se quedó a mitad del camino cuando identificaba derecho con poder para vencer el temor, la inseguridad y los riesgos de la supervivencia como tarea exclusiva de cada uno, sin pensar que la autoconservación es más segura y la vida individual puede ser más tranquila, próspera y feliz cuando cuenta con y se basa en la ayuda y colaboración de los otros; cuando, debido a nuestra trascendencia, cada uno toma su autoconservación y la satisfacción de sus deseos como tarea colectiva. Pero Hobbes no lo vio así y no vio que esta dimensión solidaria, según mi propia concepción an- tropológica, no es convencional sino constitutiva, es la manera de ser nuestra naturaleza humana. Ahora el egoísmo primero ya no tiene el signo negativo de la hostilidad y de la agresión habitual e indiscriminada, y el propio interés es ahora confianza y colaboración positiva en el interés del otro. No se trata de un utilitarismo interesado, sino de la dimensión profunda de la dialéctica individuo/sociedad, o más radicalmente, de la dialéctica de su naturaleza individual y social, de su inmanencia y trascendencia. Esta dialéctica significa que no hay contradicción entre los individuos, la cual nos arrojaría sin remedio al bellum omnium, sino que hay afirmación y negación recíproca entre los hombres desde su inmanencia y trascendencia, y por la cual cada uno está implicado activamente, por naturaleza, en la supervivencia, autorrealización y plenitud de los demás. Nuestra supervivencia y autorrealización sólo es posible como co-realización; por naturaleza, no por convención o contrato. Por eso, la solución de Hobbes al problema del derecho, de la hostilidad recíproca, de la locura, de la estupidez del homo lupus, introduciendo el imperio de la racionalidad, de la ley y del orden, es sólo una ficción contractualista ineficaz cuando no se ha reconocido que es la propia naturaleza humana de cada uno, individual y social, pasional y racional, la que necesita y exige regular, mediante el derecho y la ley, la vida individual y social como autoconservación individual recíproca.

\section{NOTAS}

1 Ortega y Gasset, J., En torno a Galileo, lección 6 «Cambio y crisis», Obras Completas, v. V, Madrid,

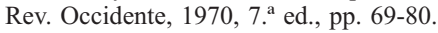

2 Bernhard, J., «Hobbes», en F. Châtelet, dtor., Historia de la filosofia, Madrid, Espasa-Calpe, 1976, v. II, pp. 131-132.

\footnotetext{
3 Giner, S., Historia del pensamiento social, Barcelona, Ed. Ariel, 1967, p. 243.

4 Gilson y Langan, Filosofia moderna, Buenos Aires, Ed. Emecé, 1967, p. 53.

5 Hobbes, Th., Del ciudadano, Caracas, Inst. de Est. Políticos, Univ. Central de Venezuela, 1966,
} 
p. 45. Sin embargo, A.E. Taylor, entre otros autores, disocia las doctrinas física y psicológica de la teoría política, cfr. «The ethical doctrine of Hobbes», Philosophy, XIII, 1938.

6 Bobbio, N., «Introducción» a Th. Hobbes, Del ciudadano, op. cit., p. 13.

7 Arendt, H., Los origenes del totalitarismo, Madrid, Ed. Taurus, 1974, p. 200.

8 Bermudo, J. M., «Hobbes o el sombrío esfuerzo de pensar la autoridad», J. M. Bermudo, dtor., Los $f i$ lósofos y sus filosofias, Barcelona, Ed. Vicens Vives, 1983 , p. 115.

9 Hobbes, Th., Leviatán, Madrid, Editora Nacional, 1979, p. 207.

10 Arendt, H., op. cit., pp. 198-199. Pero hay un detalle a tener en cuenta según Arendt: «lo que más deseaba Hobbes era proteger los intereses particulares... mientras que, por el contrario, los regímenes totalitarios proclaman la inexistencia de la esfera privada», ibid., nota 36 .

${ }_{11}$ Cfr. mi artículo «Lectura dialéctica de Rousseau desde la antinomia antropológica individuo/sociedad», Studium. Revista de Humanidades, Facultad de Humanidades y Ciencias Sociales, Univ. Zaragoza, n. ${ }^{\circ} 7$, 2000, pp. 33-66.

12 Hobbes, Th., Leviatán, op. cit., p. 189.

13 Id., Elementos del derecho moral y político, Madrid, Centro de Estudios Constitucionales, 1979, pp. 150-151.

14 Id., Leviatán, op. cit., pp. 190-191.

15 Ibid., p. 195.

16 Id., Elementos..., op. cit., p. 236.

17 Id., Leviatán, op. cit., p. 224.

18 Ibid., pp. 227-228.

19 Id., Del ciudadano, op. cit., p. 68.

20 Ibid., p. 66.

21 Id., Elementos..., op. cit., p. 203.

22 Id., Del Ciudadano, op. cit., p. 74.

23 Ibid., pp. 74-75.

${ }^{24}$ Ibid., p. 74, nota.

25 Id., Elementos..., op. cit., p. 210.

26 Ibid., p. 210.

27 Id., Del ciudadano, op. cit., p. 98, nota 2.

28 Id., Elementos..., op. cit., p. 244.

29 Id., Leviatán, op. cit., pp. 228-229.

30 Ibid., p. 252.

31 Id., Del ciudadano, op. cit., p. 99.

32 Id., Leviatán, op. cit., p. 253.

33 Id., Elementos..., op. cit., p. 233.

34 Id., Leviatán, op. cit., p. 364, y Elementos..., op. cit., p. 237.

35 Giner, S., op. cit., p. 243.

36 Hobbes, Th., Del ciudadano, op. cit., p. 66.

37 Id., Leviatán, op. cit., p. 225.
38 Bobbio, N., op. cit., pp. 20-21.

39 Hobbes, Th., Elementos..., p. 205.

40 Id., Del ciudadano, op. cit., p. 71.

41 Id., Elementos..., op. cit., pp. 175 y 176.

42 Id., Leviatán, op. cit., p. 373.

43 Bobbio, N., op. cit., p. 26. Bernhard se refiere en este sentido al «recíproco desbordamiento de los derechos naturales», J. Bernhard, op. cit., p. 133.

44 Hobbes, Th., Leviatán, op. cit., p. 277.

45 Id., Del ciudadano, op. cit., pp. 74-75, nota.

46 Sabine, S., op. cit., p. 345.

47 Baier, K., The moral point of view, Ithaca and London, Cornell University Press, 1958, p. 314.

48 Ibid., pp. 314-315.

49 Guisán, E., «Ética y política en Hobbes», ponencia presentada en la I Semana de Ética, Santiago de Compostela, 1979.

50 Macpherson, C. B., La teoría política del individualismo posesivo, Barna, E. Fontanella, 1970, p. 31.

51 Strauss, L., The political philosophy of Hobbes, Oxford University Press, 1936.

52 Macpherson, C. B., op. cit., p. 48.

53 Sabine, G., op. cit., p. 344.

54 Hobbes, Th., Leviatán, op. cit., p. 267.

55 Gauthier, D. P., The logic of Leviatan, Oxford University Press, 1969. Criterio que, a su manera, recoge B. Russell: la única justificación del Gobierno es que de no existir no se deduciría la ausencia de fuerza en las relaciones de unos hombres con otros, sino que «sería solamente el ejercicio de la fuerza por aquellos que tuviesen fuertes instintos rapaces», B. Russell, Ideales políticos, M., Aguilar, 1968, p.25.

56 Oakeshott, M., «Introduction» a Th. Hobbes, Leviatan, Oxford University Press, 1947. Véase también su Hobbes on civil association, Oxford, Basil Blackwell, 1975.

57 Warrender, H., The political philosophy of Hobbes: his theory of obligation, Oxford, 1957.

58 Desde un criterio y visión igualmente históricos es juzgada críticamente esta misma teoría por MacIntyre porque «es sorprendente que Hobbes se impresione tanto por el hecho de la guerra civil y tan poco por las metas declaradas y confesadas de quienes participaban en ellas. Pero no se impresionó y esto se debe a que su teoría de los móviles lo llevó a suponer que los elevados ideales necesariamente no eran más que una máscara para el impulso de dominación. Por lo tanto, no da importancia a la aparición de la libertad como ideal y como meta, y así no advierte el más importante cambio social en la historia de esta época», A. MacIntyre, Historia de la ética, Buenos Aires, 1978, p. 138.

59 MacIntyre, A., op. cit., p. 136. 